\title{
Adolescent Girls Empowerment Program (AGEP): Nutrition
}

Paul C. Hewett

Population Council

Amanda L. Willig

Jean Digitale

Population Council

Erica Soler-Hampejsek

Natalie Jackson Hachonda

Population Council

See next page for additional authors

Follow this and additional works at: https://knowledgecommons.popcouncil.org/departments_sbsr-pgy

Part of the Demography, Population, and Ecology Commons, Family, Life Course, and Society Commons, International Public Health Commons, and the Maternal and Child Health Commons How does access to this work benefit you? Let us know!

\section{Recommended Citation}

Hewett, Paul C., Amanda L. Willig, Jean Digitale, Erica Soler-Hampejsek, Natalie Jackson Hachonda, Jere R. Behrman, and Karen Austrian. 2018. "Adolescent Girls Empowerment Program (AGEP): Nutrition," brief. Lusaka: Population Council. 


\section{Authors}

Paul C. Hewett, Amanda L. Willig, Jean Digitale, Erica Soler-Hampejsek, Natalie Jackson Hachonda, Jere R. Behrman, and Karen Austrian 
Adolescence is a critical period in the lives of young people and potentially a time to reap lasting benefits from interventions that improve general, sexual, nutritional, and maternal and child health. As suggested in the 2013 Lancet series on nutrition, the focus on nutritional interventions for adolescents is warranted because "interventions to improve nutrition and child development during this period have high rates of return." ${ }^{1}$ This conclusion is based on the recognition of nutrition's effect on future productivity, maternal and child health, and child growth and cognitive development. Nutrition during adolescence plays a significant role in the empowerment of girls and young women and the health of their future families. ${ }^{2}$

\section{BACKGROUND}

The government of Zambia is committed to improving the nutritional status of adolescents, and pregnant women and their children. Nonetheless, adolescent girls in Zambia remain at risk for macro- and micro-nutrient deficiencies that have deleterious effects on growth, development, and maternal and child health. ${ }^{3-5}$ Among nonpregnant adolescents aged 15-19 in Zambia, 16\% are undernourished (5\% severely), and 3\% are stunted (short for their age). ${ }^{3}$ Among children less than 5 years old, 40\% experience stunting and $15 \%$ are underweight for their age. ${ }^{3}$ In particular, a high prevalence of anemia (28\%) has been reported among reproductive-age women, including adolescents. ${ }^{3}$ Dietary iron needs increase during adolescence, and iron-deficient anemia in

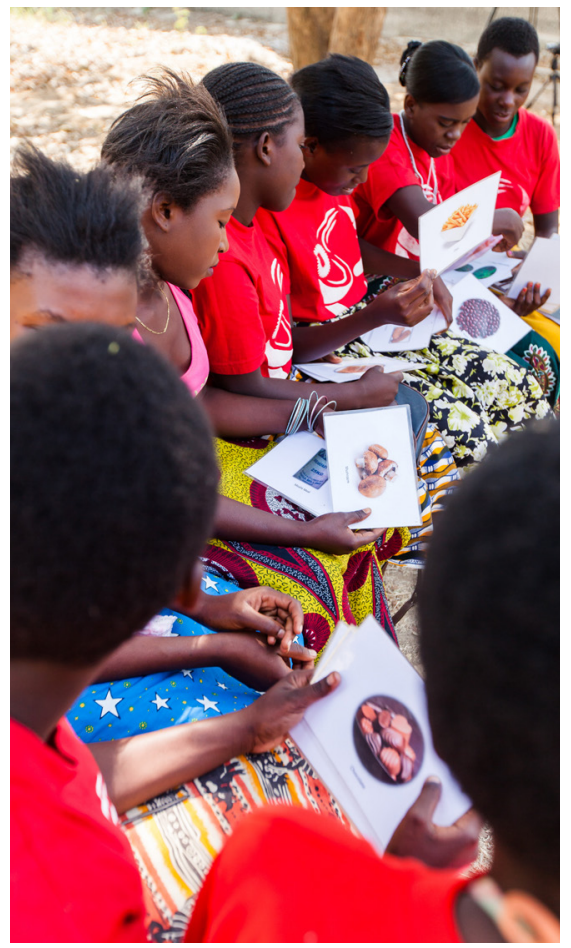
late childhood and adolescence is associated with neurological impairment, lower physical endurance, and decreased immune function. ${ }^{4,6-9}$ Additionally, anemia in pregnant adolescents can result in premature births and low birth-weight, with offspring further at risk for anemia-related cognitive and growth deficits. ${ }^{10}$ In Zambia, an estimated 29\% of girls aged 15-19 have experienced pregnancy, yet only 55\% of pregnant adolescents of this age who had a birth in the previous five years used oral iron supplementation for 90 or more days during their last pregnancy, with $4 \%$ not using any iron supplements during their pregnancy. ${ }^{3}$

\section{ADOLESCENT GIRLS EMPOWERMENT PROGRAM (AGEP)}

The AGEP intervention was conducted over two years to support more than 11,000 vulnerable ${ }^{a}$ adolescent girls in Zambia with social, health, and economic asset-building activities. The intervention was led by the Population Council, in partnership with the Young Women's Christian Association of Zambia (YWCA), the National Savings

\footnotetext{
a In AGEP, "vulnerable" was defined as the number of years a girl was lagging behind in her schooling relative to her age, taking into account several individual and household factors. See 2016 Population Council brief "Methodology: Reaching the Most Vulnerable Adolescent Girls."
} 


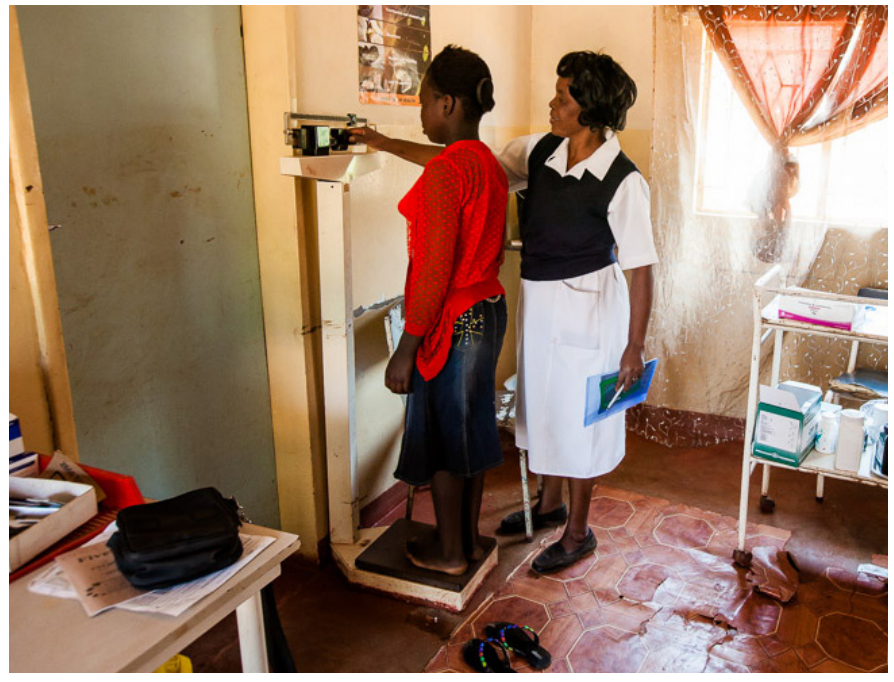

and Credit Bank of Zambia (Natsave), and the Government of Zambia. AGEP was implemented in ten sites within urban and rural areas in four provinces in Zambia. One major component of AGEP was weekly safe space groups in which girls met over the course of two years to engage with each other and a mentor following curricula-guided topics such as health, life skills, financial education, and nutrition.

The AGEP nutritional curriculum, developed in partnership with PATH, was tailored to provide age-appropriate information and covered six sessions on nutrition: 1) Nutritional Needs for Adolescent Girls; 2) Role of Food in the Body; 3) Anemia in Adolescent Girls; 4) Nutrition for Pregnant Adolescents; 5) Infant Feeding from Birth through Six Months; and 6) Young Child Feeding and Growth Monitoring. Girls aged 15-19 years took part in all six sessions, while girls aged 10-14 years participated in the first three sessions. Sessions were conducted over consecutive weeks during the first year of the program and were repeated again in the second year. The curriculum used innovative educational and interactive components whose objective was to maximize girls' knowledge acquisition and engagement, without being didactic. This brief summarizes the impact of the nutrition curriculum on nutrition outcomes of adolescents and their children one year after the AGEP program ended.

To assess the impact of the nutritional education curricuIum, approximately half of the AGEP mentors were randomized to include the nutritional education within their safe spaces groups. The randomization allows for a rigorous assessment of the impact of the educational component on key nutritional outcomes, including knowledge, dietary intake, anthropometry, and anemia. The nutrition-focused analysis compared girls who attended an AGEP group that received the nutrition curriculum to girls who attended an AGEP group that did not receive the nutrition curriculum. This assessment was embedded within the ongoing broader study evaluating the impact of the AGEP program, including a cohort of girls who were 10-19 in 2013/14 and interviewed annually over the course of four years. ${ }^{10}$
FIGURE 1. NUTRITION OUTCOMES FOR ADOLESCENT GIRLS IN AGEP

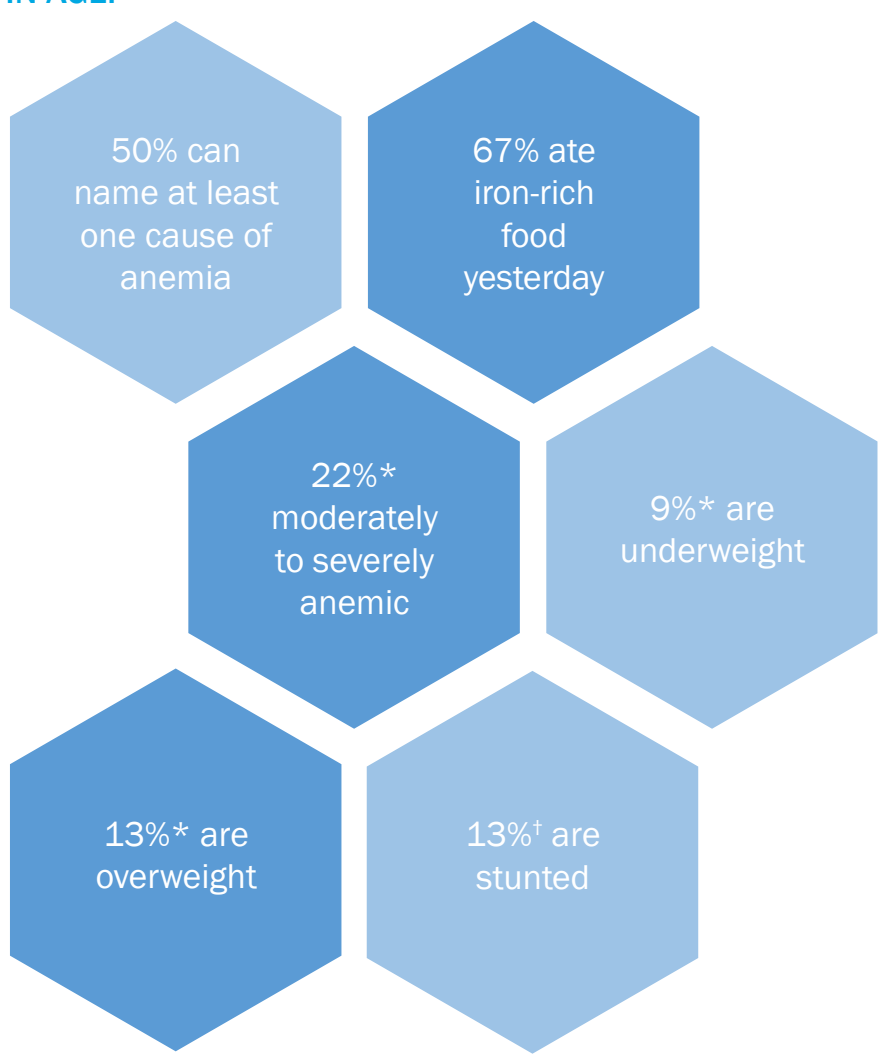

* Age 15-19 baseline cohort

${ }^{\dagger}$ Age 10-14 baseline cohort

\section{RESULTS}

The results indicate that exposure to the nutritional curriculum had limited influence on nutritional outcomes for adolescents. Furthermore, the impacts were no different for girls who had greater exposure to the nutritional curriculum, as measured by attending at least two-thirds of the sessions. While there was a statistically significant increase in adolescent knowledge of causes and symptoms of anemia, no other significant changes in knowledge were observed.

Exposure to the nutritional curriculum also did not influence dietary diversity or the types of food eaten. While dietary diversity, eating iron-rich foods, and eating food rich in Vitamin A increased over time, the positive change was similar for girls who did and did not receive the intervention. The nutrition curriculum also did not affect anthropometric indicators or anemia. Of note is the fact that as the cohort of girls aged over time, they were less likely to be stunted or underweight, and more likely to be overweight. Anemia was also found to be prevalent in more than one in five girls.

The nutritional status of children under five, whose mothers were part of the AGEP research sample, indicates a range of nutritional concerns. More than $40 \%$ of children of adolescents in the study were stunted. A sizable percentage $(12 \%)$ of the sample was underweight and $4 \%$ of children under five years can be classified as wasted (thin for height). Additionally, half (51\%) of the children had 
- In Zambia, the nutritional status of the children of adolescent girls is concerning, with particularly high rates of anemia.

- Select girls in the AGEP program received between three and six interactive, educational sessions on nutrition, and we assessed the impact of this intervention on nutritional outcomes.

- Despite the life-stage-appropriate and interactive nutritional education sessions, the nutritional education information "did not stick" with the adolescents, and it did not translate into changes in behavior or subsequently to better nutritional outcomes.

- Addressing the context that shapes girls' approach to nutrition-including relatable information, access to and control over food, and economic empowerment and control of resources within the householdrequires further consideration for programs attempting to improve nutritional programs for adolescents and their children.

moderate or severe anemia. The intervention showed no effects on the nutritional status of children whose mothers had participated in the nutrition intervention; it did not improve indicators such as stunting, wasting, underweight, or anemia. Additionally, there were no significant changes in the dietary intake of the children, either through increased breastfeeding or through increases in intake of iron-rich foods.

\section{CONCLUSION}

The results of this rigorous randomized evaluation indicate that the AGEP nutrition training component with context-relevant participatory and interactive educational sessions did not improve adolescent or child nutritional outcomes. First and foremost, the intervention did not change adolescent nutritional knowledge as was expected. The lack of improvement in knowledge may partially explain why change was not observed in dietary behavior and nutritional outcomes, such as undernutrition and anemia among the adolescent girls and their children. In addition, the intervention did not address the contextual factors that could affect a girl's nutritional intake. As girls are largely not the ones who determine the food purchased for and consumed within the household, it is possible that improving the knowledge and economic ability of the household members who determine the diet of the household may lead to change on nutrition outcomes for girls still living with their parents/guardians. Those living on their own may need further economic strengthening activities to be able to make changes in their nutritional behaviors.

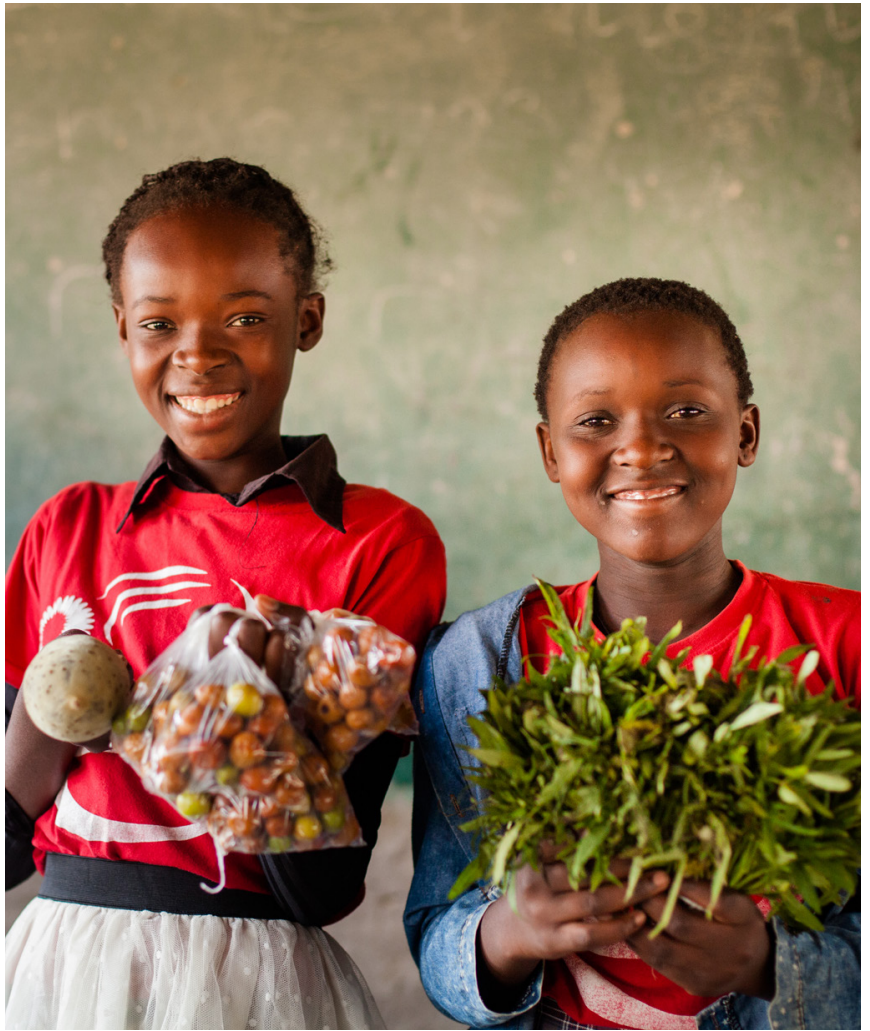

The results indicate that high-quality, fact-based, nutritional educational programs for adolescents on their own do not assure increased knowledge, changes in nutritional intake, or improvements in anemia status, and that care is needed in designing programs to address not only the information that adolescents need on nutrition, but also the surrounding context that determines their diet and other nutrition outcomes.

\section{REFERENCES}

1. Ruel, M.T., H. Alderman, and Maternal, Child, and Nutrition Study. 2013. "Nutrition-sensitive interventions and programmes: How can they help accelerate progress in improving maternal and child nutrition?" The Lancet 382(9891): 536-551.

2. Taylor, A, A.D. Dangour, and K.S. Reddy. 2013. "Only collective action will end undernutrition," The Lancet 382(9891): 490-491.

3. Central Statistical Office (CSO), MOH [Zambia], and ICF International. 2014. Zambia Demographic and Health Survey 2013-2014. Rockville, MD, USA: CSO, MOH, and ICF International.

4. Brabin, L. and B.J. Brabin. 1992. "The cost of successful adolescent growth and development in girls in relation to iron and vitamin A status," The American Journal of Clinical Nutrition" 55(5): 955-958. 
5. Ji, X., N. Cui, and J. Liu. 2017. "Neurocognitive function is associated with serum iron status in early adolescents," Biological Research for Nursing 19(3): 269-277.

6. Grantham-McGregor, S.M. and C.C. Ani. 1999. "The role of micronutrients in psychomotor and cognitive development," British Medical Bulletin 55(3): 511-527.

7. Bruner, A.B., A. Joffe, A.K. Duggan, J.F. Casella, and J. Brandt. 1996. "Randomised study of cognitive effects of iron supplementation in non-anaemic iron-deficient adolescent girls," The Lancet 348(9033): 992-996.

8. Rowland, T.W., M.B. Deisroth, G.M. Green, and J.F. Kelleher. 1988. "The effect of iron therapy on the exercise capacity of nonanemic iron-deficient adolescent runners," American Journal of Diseases of Children 142(2): 165-169.

9. Ekiz, C., L. Agaoglu, Z. Karakas, N. Gurel, and I. Yalcin. 2005. "The effect of iron deficiency anemia on the function of the immune system," The Hematology Journal: The Official Journal of the European Haematology Association 5(7): 579-583.

10. Hewett, P.C., K. Austrian, E. Soler-Hampejsek, J.R. Behrman, F. Bozzani, and N.A. Jackson-Hachonda. 2017. "Cluster randomized evaluation of Adolescent Girls Empowerment Programme (AGEP): Study protocol," BMC Public Health 17(1): 386.

Authors: Paul C. Hewett, Amanda L. Willig, Jean Digitale, Erica Soler-Hampejsek, Natalie Jackson Hachonda, Jere R. Behrman, and Karen Austrian.

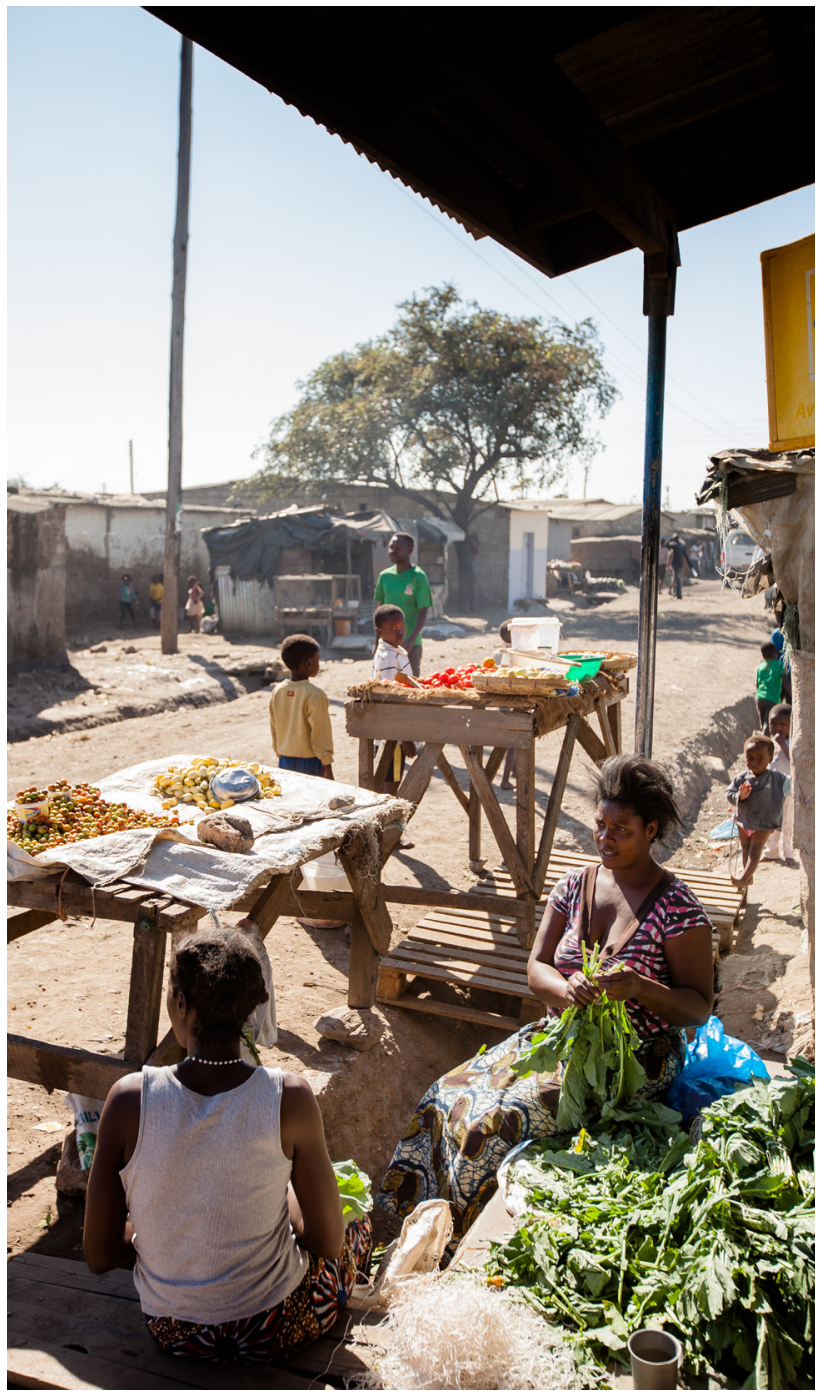

\section{CONTACT INFORMATION}

For more information about AGEP, call +260 211295925

or email: info@popcouncil.org or visit: http://www.popcouncil.org/research/ adolescent-girls-empowerment-program
Population Council

Plot \#3670 No. 4 Mwaleshi Road

Olympic Park

Lusaka, Zambia 10101 